\title{
The effects of age on sperm quality: an evaluation of 1,500 semen samples
}

\author{
João Batista A. Oliveira ${ }^{1,2}$, Claudia G. Petersen ${ }^{1,2}$, Ana L. Mauri ${ }^{1,2}$, Laura D. Vagnini ${ }^{2}$, Ricardo L. R. Baruffi ${ }^{1,2}$, \\ José G. Franco Jr. ${ }^{1,2}$ \\ ${ }^{1}$ Center for Human Reproduction Prof. Franco Jr., Ribeirao Preto, SP, Brazil \\ 2Paulista Center for Diagnosis Research and Training, Ribeirao Preto, SP, Brazil
}

Oral Presentation - ESHRE 29th Annual Meeting - London 2013

\begin{abstract}
Objective: The aim of this study was to evaluate the effects of aging on semen quality in a population of infertile couples.

Methods: A cross-sectional study of semen samples obtained from 1,500 men randomly selected from couples who attended an infertility clinic was conducted. The analyses were performed using Spearman's correlation and Mann-Whitney tests. The age groups consisted of men $\leq 35$ years, from $36-45$ years and > 45 years of age. The semen analysis was performed according to the WHO criteria, and morphology was evaluated using the motile sperm organelle morphology examination (MSOME). The percentages of normal spermatozoa and spermatozoa with large nuclear vacuoles (LNV, occupying > 50\% nuclear area) were determined. The percentages of DNA fragmentation were assessed using the TUNEL assay.

Results: A regression analysis revealed that the percentages of LNV spermatozoa and sperm DNA fragmentation positively correlated with age. Conversely, a regression analysis revealed that the percentage of normal sperm, sperm progressive motility and sperm vitality negatively correlated with age. As in the previous test, the analysis by age group showed that there was a significant reduction $(P<0.05)$ in the percentage of normal sperm, sperm progressive motility and sperm vitality as age increased. Conversely, the percentage of spermatozoa with LNVs and sperm DNA fragmentation significantly increased $(P<0.05)$ as age increased. Conclusion: Semen quality seems to be influenced by aging. The age-related decrease in sperm quality suggests that delaying childbearing, not only for women but also for men, may jeopardize reproductive capacity.
\end{abstract}

Keywords: age, sperm parameters, DNA fragmentation, sperm quality, MSOME

\section{INTRODUCTION}

As a result of the increase in life expectancy and the changing roles of women in society, delaying the onset of reproductive life has become a more common trend, especially in developed countries. However, the increase in the age of couples also brings an increase in reproductive risks. Society has reacted to the increase in maternal age with certain actions such as imposing restrictions on access to fertility treatment for women over the age of 40 years or offering screening tests during pregnancy for fetal malformations. Yet, such precautions are not practiced for older males. Names such as Picasso and Chaplin, who were parents in their old age, are inevitably cited as examples when the reproductive functions of older men are questioned. In addition, statistics show a large number of children born to fathers older than 50 years of age in the general population. However, even considering the discrepancy between the reproductive periods of men and women, the question has been raised as to whether advanced male age is also associated with impaired fertility and/or risks to pregnancy. The evaluation of male fertility is generally based on the examination of sperm parameters. Although there is no known critical age limit for gamete production for men, evidence suggests that there are declines in semen quality (e.g., volume, motility and morphology) and male fertility associated with increasing male age (Andolz et al., 1999; Girsh et al., 2008; Dain et al., 2011; Zhu et al., 2011). However, there is no consensus among the published results. Therefore, studies examining the relationship between age and semen quality and/or fertility continue to be important. Conversely, advanced paternal age has been implicated in the increase in the frequencies of abortions (Slama et al., 2005; Kleinhaus et al., 2006), autosomal dominant diseases, aneuploidy and other diseases (Wyrobek et al., 2006; Crosnoe \& Kim, 2013; Paul \& Robaire, 2013). Advanced male age has also been correlated with infant mortality (Urhoj et al., 2014). One plausible explanation for these results is that older men may have more sperm with damaged DNA (Vagnini et al., 2007). Chromatin damage has been associated with male infertility, conception problems and problems sustaining pregnancy (Zini \& Libman, 2006; Ménézo et al., 2007; Das et al., 2013). There is also evidence linking DNA damage in sperm with the risk of mutations and birth defects in the offspring (Wyrobek et al., 2006; Paul \& Robaire, 2013).

Understanding the effects of age on fertility is particularly relevant given that the increase in life expectancy and the availability of assisted reproductive technologies have increased the opportunities for men to have children at older ages. Thus, the aim of this study was to investigate the influence of age on sperm quality in a group of men diagnosed with or under treatment for infertility.

\section{MATERIAL AND METHODS \\ Population}

Semen samples (one per subject) were obtained from 1500 men from a random group of couples undergoing infertility investigation and treatment. Written informed consent was obtained from all participants, and the local ethical committee Institutional Review Board approved this study.

\section{Sample collection}

Semen samples were collected in sterile containers by masturbation after a sexual abstinence period of 2-5 days. A portion of each semen sample was used to analyze the following parameters according to the World Health Organization (WHO) guidelines (2010): volume (ml), sperm concentration $\left(x 10^{6} / \mathrm{ml}\right)$, percentage of spermatozoa with progressive motility (rapid + slow progression) and percentage of live spermatozoa (vitality).

The remainder of the semen sample was processed for morphological analysis following motile sperm organelle morphology examination (MSOME) and for sperm DNA fragmentation analysis measured using the TdT (terminal 

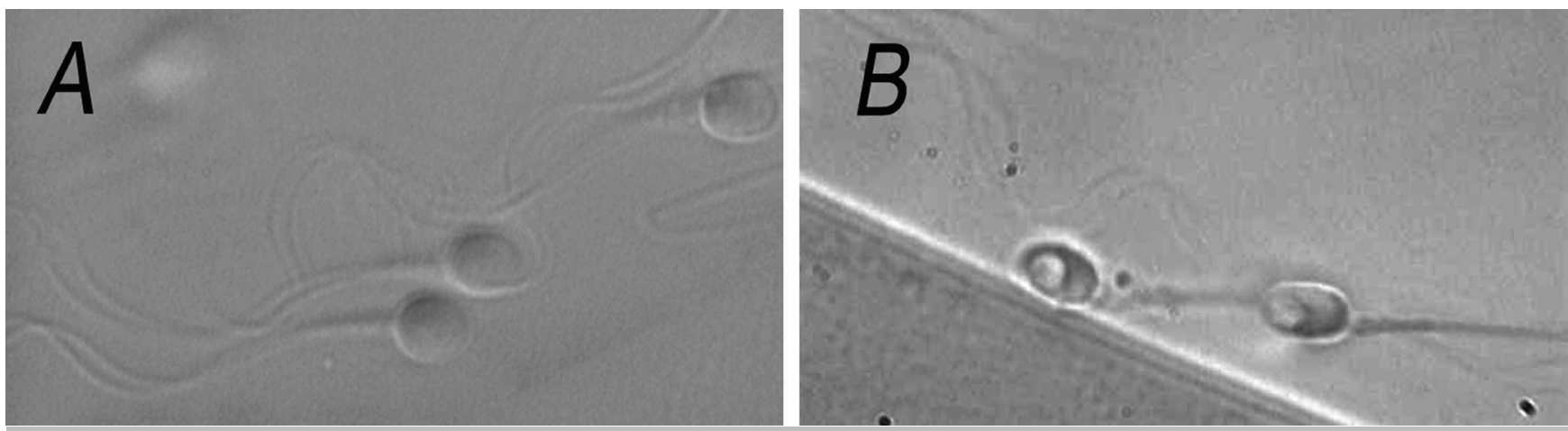

Figure 1. MSOME for human sperm morphology analysis $(8,450 x)$. A) Normal spermatozoa observed at high magnification; (B) Spermatozoa with large nuclear vacuoles at high magnification.

deoxyribonucleotidyl transferase)-mediated dUTP nick-end labeling (TUNEL) assay.

\section{Determination of morphology by MSOME}

The liquefied fresh semen samples were prepared using an Isolate (Irvine Scientific, USA) discontinuous concentration gradient. The final pellet was resuspended in $0.2 \mathrm{ml}$ of modified human tubal fluid (HTF) medium (Irvine Scientific, Santa Ana, CA, USA). An aliquot of $1 \mu$ l of sperm cell suspension was transferred to a $5 \mu \mathrm{l}$ microdroplet of modified HTF medium containing 7\% polyvinylpyrrolidone (PVP medium; Irvine Scientific). This microdroplet was placed in a sterile glass dish (Fluorodish; World Precision Instruments, USA) under sterile paraffin oil (Ovoil-100; VitroLife, Goteborg, Sweden). The sperm cells, which were suspended in the microdroplet, were placed on a microscope stage above a U Plan Apochromat $100 \mathrm{x}$ oil/ 1.35 objective lens that had previously been covered by a droplet of immersion oil. With this procedure, the suspended motile sperm cells in the observation droplet could be examined at high magnification using an inverted microscope (Eclipse TE $2000 \mathrm{U}$; Nikon, Japan) equipped with high-power differential interference contrast optics (DIC/Nomarski). The images were captured by a color video camera that had sufficient resolution to produce high-quality images, which were displayed on a color video monitor. The morphological evaluation was performed on the monitor screen, and the combined calculated magnification was $8450 x$ (total magnification: objective magnification $=100 \times$; magnification selector $=1.0 \mathrm{x}$; video coupler magnification $=1.0 \mathrm{x}$; calculated video magnification $=84.50$ ).

Two types of spermatozoa observed via MSOME were counted in this study: normal spermatozoa and spermatozoa with large nuclear vacuoles (LNVs). A spermatozoon was classified as morphologically normal when it exhibited a normal nucleus as well as a normal acrosome, post-acrosomal lamina, neck and tail and had no cytoplasm around the head (Bartoov et al., 2002). The morphological state of the nucleus was defined by its shape and chromatin content, as assessed by transmission electron microscopy estimations. The normal nuclear shape was defined as a smooth, symmetric oval. The normal means for length and width were estimated as $4.75 \pm 2.8$ and $3.28 \pm 0.20$ $\mu \mathrm{m}$ (Bartoov et al., 2002), respectively, and forms classified as abnormal varied by two standard deviations (SD) in at least one of the axes (length: $\geq 5.31$ or $\leq 4.19 \mu \mathrm{m}$, width: $>3.7$ or $<2.9 \mu \mathrm{m}$ ). The criterion for normality of chromatin content was the absence of vacuoles occupying $>4 \%$ of the sperm nuclear area. Figure $1 \mathrm{~A}$ shows normal spermatozoa analyzed by MSOME.

LNV spermatozoa were defined according to the Bartoov modified classification, i.e., the presence of one or more vacuoles occupying $>50 \%$ of the sperm nuclear area (visual evaluation aided, if necessary, by a celluloid form of a large vacuole superimposed on the examined cell). Figure $1 \mathrm{~B}$ shows LNV spermatozoa analyzed using MSOME.

The same technician performed all semen sample evaluations. As in other sperm morphological analyses, each sperm was evaluated/classified individually in MSOME, and the process was carried out directly on the monitor screen. At least 200 motile spermatozoa per sample were evaluated, and the percentages of normal and LNV spermatozoa were determined.

\section{Determination of DNA damage}

DNA fragmentation in the spermatozoa was measured using the TUNEL assay, which was performed using a Cell Death Detection Kit with tetramethylrhodamine-labelled dUTP (Roche, Monza, Italy). TUNEL identifies single- and double-stranded DNA breaks by labeling the free 3 '-OH termini with modified nucleotides in an enzymatic reaction with TdT. TdT polymerizes free 3-OH DNA ends in a template-independent manner, incorporating labeled nucleotides. The remaining sperm pellets were smeared on glass slides, air-dried, fixed with $4 \%$ paraformaldehyde in PBS at $4^{\circ} \mathrm{C}$ for $25 \mathrm{~min}, \mathrm{pH} 7.4$, and permeabilized with $0.1 \%$ Triton X-100 (VETEC Química Fina Ltd, Duque de Caxias, Brazil) in $0.1 \%$ sodium citrate at $4^{\circ} \mathrm{C}$ for 2 min. After washing with PBS, the smears were then processed for the TUNEL assay. The TdT-labeled nucleotide mix was added to each slide and incubated in the dark in a humidified atmosphere for $2 \mathrm{~h}$ at $37^{\circ} \mathrm{C}$. After stopping the enzyme reaction, the slides were rinsed twice in PBS and then counterstained

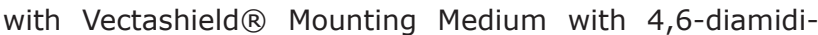
no-2-phenylindole (DAPI; $1.5 \mu \mathrm{g} / \mathrm{ml}$ ) (Vector Laboratories, Burlingame, CA, USA). For quantitative evaluation, at least 200 spermatozoa in randomly selected areas on microscope slides were evaluated using a fluorescent microscope, and the percentage of TUNEL-positive spermatozoa was determined. The number of cells per field stained with DAPI (blue) was counted first; the number of cells with red fluorescence (TUNEL positive) was expressed as a percentage of the total sample. Controls were included in every experiment: for the negative control, TdT was omitted from the nucleotide mix. Positive controls were generated by pre-incubating the fixed and permeabilized sperm cells using DNaseI at $1 \mathrm{mg} / \mathrm{ml}$ (New England Biolabs, Inc, Ipswich, MA, USA) for $30 \mathrm{~min}$ at $37^{\circ} \mathrm{C}$. The TUNEL labeling of positive controls varied from $89-98 \%$ of the cells. The same technician, blinded to the subject identity, performed all the examinations.

Statistical analysis

The data were analyzed using the StatsDirect statistical 
software (Cheshire, UK). The Mann-Whitney U test, Student's t-test and the chi-squared test were used as appropriate. Correlations were performed using the Spearman rank correlation test. Patient age and percentages of normal and LNV spermatozoa, volume, sperm concentration, percentage of progressive motility and vitality were treated as continuous variables for the regression and correlation analysis. For two-group comparisons, the following ages were used as cut-off points to divide the subjects into groups: Group I: $\leq 35$ years, Group II: $36-45$ years, and Group III: $>45$ years. The level of significance was set at $P<0.05$.

\section{RESULTS}

Table 1 summarizes the general characteristics of the study population. The comparison between the three age groups showed that a significantly higher proportion of older men had fathered at least one child (or generated a pregnancy that had ended in miscarriage), spontaneously or after fertility treatment, compared with the younger men. Similarly, an increase in the length of the infertile period was also observed with increasing age.

Table 2 summarizes the results of the two-group comparisons. An influence of aging on sperm concentration was not observed. However, the semen volume, the progressive motility and the vitality of sperm worsened with age. The overall percentage of sperm volume was $2.9 \pm 1.4$ $\mathrm{ml}$ (range $0.5-9.5 \mathrm{ml}$ ). The mean volume was $3.0 \pm 1.4$ $\mathrm{ml}$ (range 0.5-9.5 ml) in Group I, $2.9 \pm 1.3 \mathrm{ml}$ (range $0.5-8.5 \mathrm{ml}$ ) in Group II and $2.5 \pm 1.4 \mathrm{ml}$ (range $0.5-7 \mathrm{ml}$ ) in Group III. There was no difference in the semen volume between the younger (I and II) groups $(P=0.56)$. The volume in the older group (III) was significantly lower than those in both of the younger (I and II) groups $(P<0.0001$ and $P<0.0001$, respectively). The overall percentage of sperm progressive motility was $56.9 \pm 17.3 \%$ (range $0-95 \%)$. The mean progressive motility was $58.9 \pm 16.5 \%$ (range 0-95\%) in Group I, $56.3 \pm 17.2 \%$ (range 0-95\%) in Group II and $51.8 \pm 19.5 \%$ (range $0-85 \%$ ) in Group III.
There were significant differences in the progressive motility among the three groups (Group I X Group II: $P=0.003$; Group I X Group III: $P=<0.0001$; Group II X Group III: $P=0.01)$. The overall percentage of sperm vitality was $64.6 \pm 15.6 \%$ (range $0-98 \%$ ). The mean vitality was 66.7 $\pm 14.6 \%$ (range 0-97\%) in Group I, $64.0 \pm 15.3 \%$ (range $0-98 \%$ ) in Group II and $60.1 \pm 18.3 \%$ (range $0-86 \%$ ) in Group III. Similar to sperm motility, there were significant differences in the sperm vitality among the three groups (Group I X Group II $P=0.0002$; Group I X Group III $P=<$ 0.0001; Group II X Group III $P=0.03$ ).

The overall percentage of sperm with normal form, as analyzed by MSOME, was $1.03 \pm 1.7 \%$ (range $0-15 \%$ ). The mean percentage of sperm with a normal form was 1.11 $\pm 1.9 \%$ (range $0-15 \%$ ) in Group I, $1.05 \pm 1.7 \%$ (range $0-11 \%$ ) in Group II and $0.69 \pm 1.0$ (range $0-8 \%$ ) in Group III. There was no difference in the percentage of normal sperm in the two younger (I and II) groups $(P=0.49)$ or between groups II and III $(P=0.10)$. However, the percentage of normal sperm in the older group (III) was significantly lower than those in either of the younger (I) groups $(P=0.03)$. The overall percentage of LNV spermatozoa was $31.6 \pm 19.7 \%$ (range $2-100 \%$ ). The mean percentages of LNV spermatozoa were $30.4 \pm 18.7 \%$ (range $3-98 \%$ ) in Group I, $31.4 \pm 19.5 \%$ (range $2-100 \%$ ) in Group II and $36.5 \pm 23.1 \%$ (range 5-100\%) in Group III. There was no difference in the percentage of spermatozoa with LNVs between the younger (I and II) groups ( $P=$ 0.47). However, the percentage of spermatozoa with LNVs in the older group (III) was significantly higher than those in both of the younger (I and II) groups ( $P=0.001$ and $P$ $=0.005$, respectively).

The overall percentage of sperm DNA fragmentation was $16.2 \pm 9.3 \%$ (range 3-60\%). The mean DNA fragmentation was $15.3 \pm 9.0 \%$ (range $3-59 \%$ ) in Group I, $16.7 \pm$ $9.7 \%$ (range 3-60\%) in Group II and $16.7 \pm 8.5 \%$ (range $4-41 \%$ ) in Group III. The percentage of sperm DNA fragmentation was significantly lower in Group I than Group II $(P=0.008)$ or III $(P=0.02)$. However, there was no

Table 1. General characteristics of the three age groups studied

\begin{tabular}{|c|c|c|c|c|c|}
\hline \multirow[t]{2}{*}{ Characteristic } & \multicolumn{5}{|c|}{ Age Group } \\
\hline & Total & $\leq 35$ years & $36-45$ years & $>45$ years & $P$ \\
\hline Patients (n) & 1500 & 597 & 727 & 176 & \\
\hline Age (years) & $\begin{array}{c}37.7 \pm 6.7 \\
(22-76)\end{array}$ & $\begin{array}{c}31.8 \pm 2.7 \\
(22-35)\end{array}$ & $\begin{array}{c}39.5 \pm 2.7 \\
(36-45)\end{array}$ & $\begin{array}{c}50.6 \pm 5.3 \\
(46-76)\end{array}$ & \\
\hline Body mass index & $\begin{array}{l}28.3 \pm 4.3 \\
(17-44.1)\end{array}$ & $\begin{array}{c}28.6 \pm 4.4 \\
(17-43.1) \\
\end{array}$ & $\begin{array}{c}28.2 \pm 4.1 \\
(18.9-42.9)\end{array}$ & $\begin{array}{c}28.2 \pm 4.4 \\
(19.8-44.1) \\
\end{array}$ & ns \\
\hline $\begin{array}{l}\text { Fathered at least one } \\
\text { child }\end{array}$ & $\begin{array}{c}33.0 \% \\
(495 / 1500)\end{array}$ & $\begin{array}{l}21.8 \% \%^{A, B} \\
(130 / 597)\end{array}$ & $\begin{array}{l}37.3 \%{ }^{A, C} \\
(271 / 727)\end{array}$ & $\begin{array}{l}53.4 \%{ }^{B, C} \\
(94 / 176)\end{array}$ & $\begin{array}{c}\mathrm{A}, \mathrm{B}<0.0001 \\
{ }^{\mathrm{C}} 0.0001\end{array}$ \\
\hline $\begin{array}{l}\text { Duration of infertility } \\
\text { (years) }\end{array}$ & $\begin{array}{l}3.9 \pm 3.0 \\
(1-11)\end{array}$ & $\begin{array}{c}3.1 \pm 2.0^{A, B} \\
(1-8)\end{array}$ & $\begin{array}{c}4.1 \pm 3.0^{A} \\
(2-10)\end{array}$ & $\begin{array}{c}5.4 \pm 4.5^{\mathrm{B}} \\
(1-11)\end{array}$ & $A, B<0.0001$ \\
\hline Varicocele & $\begin{array}{c}17.1 \% \\
(257 / 1500)\end{array}$ & $\begin{array}{c}15.9 \% \\
(95 / 597)\end{array}$ & $\begin{array}{c}18.2 \% \\
(132 / 727)\end{array}$ & $\begin{array}{c}17 \% \\
(30 / 176)\end{array}$ & ns \\
\hline Tobacco use & $\begin{array}{c}11.7 \% \\
(176 / 1500)\end{array}$ & $\begin{array}{c}13.4 \% \\
(80 / 597)\end{array}$ & $\begin{array}{c}10.5 \% \\
(76 / 727)\end{array}$ & $\begin{array}{c}11.4 \% \\
(20 / 176)\end{array}$ & ns \\
\hline Regular alcohol use & $\begin{array}{c}64.1 \% \\
(962 / 1500)\end{array}$ & $\begin{array}{c}64.5 \% \\
(385 / 597)\end{array}$ & $\begin{array}{c}64.8 \% \\
(471 / 727)\end{array}$ & $\begin{array}{c}60.2 \% \\
(106 / 176)\end{array}$ & ns \\
\hline Vitamin supplement use & $\begin{array}{c}15.1 \% \\
(227 / 1500)\end{array}$ & $\begin{array}{c}15.2 \% \\
(91 / 597)\end{array}$ & $\begin{array}{c}14.7 \% \\
(107 / 727)\end{array}$ & $\begin{array}{c}16.5 \% \\
(29 / 176)\end{array}$ & ns \\
\hline
\end{tabular}


Table 2. Analysis of the three age groups studied

\begin{tabular}{|c|c|c|c|c|c|}
\hline \multirow[t]{2}{*}{ Characteristic } & \multicolumn{5}{|c|}{ Age Group } \\
\hline & Total & $\leq 35$ years & $36-45$ years & $>45$ years & $P$ \\
\hline Patients $(n)$ & 1500 & 597 & 727 & 176 & \\
\hline Abstinence (days) & $\begin{array}{c}3.6 \pm 1.0 \\
(2-5)\end{array}$ & $\begin{array}{c}3.2 \pm 1.0 \\
(2-5)\end{array}$ & $\begin{array}{c}3.5 \pm 1.0 \\
(2-5)\end{array}$ & $\begin{array}{c}4.0 \pm 2.0 \\
(2-5)\end{array}$ & ns \\
\hline Volume* (ml) & $\begin{array}{l}2.9 \pm 1.4 \\
(0.5-9.5)\end{array}$ & $\begin{array}{c}3.0 \pm 1.4^{A} \\
(0.5-9.5)\end{array}$ & $\begin{array}{c}2.9 \pm 1.3^{B} \\
(0.5-8.5)\end{array}$ & $\begin{array}{c}2.5 \pm 1.4^{\mathrm{A}, \mathrm{B}} \\
(0.5-7)\end{array}$ & ${ }^{A, B}<0.0001$ \\
\hline Concentration* (x 106/ml) & $\begin{array}{c}62.5 \pm 50.8 \\
(0.1-390)\end{array}$ & $\begin{array}{c}60.6 \pm 49.4 \\
(0.1-305)\end{array}$ & $\begin{array}{c}64.1 \pm 52.1 \\
(0.1-390)\end{array}$ & $\begin{array}{c}61.2 \pm 49.8 \\
(0.1-280)\end{array}$ & ns \\
\hline Motility* (rapid + slow progression) \% & $\begin{array}{c}56.9 \pm 17.3 \\
(0-95)\end{array}$ & $\begin{array}{c}58.9 \pm 16.5^{A, B} \\
(0-95)\end{array}$ & $\begin{array}{c}56.3 \pm 17.2^{A, C} \\
(0-95)\end{array}$ & $\begin{array}{c}51.8 \pm 19.5^{\mathrm{B}, \mathrm{C}} \\
\quad(0-85)\end{array}$ & $\begin{array}{c}\mathrm{A}<0.003 \\
{ }^{\mathrm{B}}<0.0001 \\
{ }^{\mathrm{C}} 0.01\end{array}$ \\
\hline Vitality* (\%) & $\begin{array}{c}64.6 \pm 15.6 \\
(0-98)\end{array}$ & $\begin{array}{c}66.7 \pm 14.6^{A, B} \\
(0-97)\end{array}$ & $\begin{array}{c}64.0 \pm 15.3^{A, C} \\
(0-98)\end{array}$ & $\begin{array}{c}60.1 \pm 18.3^{B, C} \\
\quad(0-86)\end{array}$ & $\begin{array}{c}{ }^{A} 0.0002 \\
{ }^{B}<0.0001 \\
{ }^{C} 0.03\end{array}$ \\
\hline Leukocytes $\left(\times 10^{6}\right)$ & $0.4 \pm 2.2$ & $0.5 \pm 3.4$ & $0.4 \pm 0.9$ & $0.3 \pm 0.5$ & ns \\
\hline $\begin{array}{l}\text { Sperm morphology** (\%) } \\
\text { Normal spermatozoa } \\
\text { Spermatozoa with LNV }\end{array}$ & $\begin{array}{c}1.03 \pm 1.7 \\
(0-15) \\
31.6 \pm 19.7 \\
(2-100)\end{array}$ & $\begin{array}{c}1.11 \pm 1.9^{\mathrm{A}} \\
(0-15) \\
30.4 \pm 18.7^{\mathrm{A}} \\
\quad(3-98)\end{array}$ & $\begin{array}{l}1.05 \pm 1.7 \\
(0-11) \\
31.4 \pm 19.5^{\mathrm{B}} \\
(2-100)\end{array}$ & $\begin{array}{c}0.69 \pm 1.0^{A} \\
(0-8) \\
36.5 \pm 23.1^{A, B} \\
(5-100)\end{array}$ & $\begin{array}{l}{ }^{\mathrm{A}} 0.03 \\
{ }^{\mathrm{A}} 0.001 \\
{ }^{\mathrm{B}} 0.0050\end{array}$ \\
\hline Sperm DNA fragmentation (\%) & $\begin{array}{c}16.2 \pm 9.3 \\
(3-60)\end{array}$ & $\begin{array}{c}15.3 \pm 9.0^{A, B} \\
(3-59)\end{array}$ & $\begin{array}{c}16.7 \pm 9.7^{A} \\
(3-60)\end{array}$ & $\begin{array}{c}16.7 \pm 8.5^{\mathrm{B}} \\
(4-41)\end{array}$ & $\begin{array}{l}{ }^{\mathrm{A}} 0.008 \\
{ }^{\mathrm{B}} 0.02\end{array}$ \\
\hline \multicolumn{6}{|c|}{$\begin{array}{l}\text { *Categorized according to the World Health Organization guidelines } \\
\text { **MSOME criteria } \\
\text { Values within rows with the same superscript letter were significantly different } \\
\text { ns: not significant }\end{array}$} \\
\hline
\end{tabular}

difference in DNA fragmentation between Groups II and III $(P=0.64)$.

The regression analysis did not show a correlation between age and sperm concentration $(P=0.39$; Spearman's rank correlation $r=0.02)$. However, significant decreases in the semen volume $(P<0.0001$; Spearman's rank correlation $\mathrm{r}=-0.10)$, progressive motility $(P<0.0001$; Spearman's rank correlation $r=-0.14)$ and sperm vitality $(P<0.0001$; Spearman's rank correlation $r=-0.15$ ) with increasing male age were observed. Figure 2 summarizes these results. In relation to sperm morphology, the regression analysis demonstrated a significant decrease in the incidence of normally formed sperm with increasing male age $(P=0.01$; Spearman's rank correlation $r=-0.10)$. However, there was a significant positive correlation between the percentage of spermatozoa with LNVs and male age $(P=0.003$, Spearman rank correlation $r=0.10)$. Similarly, the regression analysis also demonstrated a significant increase in sperm DNA fragmentation with age $(P=0.02$; Spearman's rank correlation coefficient, $r=0.10)$. Figure 3 summarizes these results.

\section{DISCUSSION}

The effect of paternal age on semen quality has been discussed in the literature, but the results are not consistent. Our results found that increased age is associated with decreases in semen volume, sperm vitality and sperm progressive motility. Several studies have reported similar results, noting an inverse correlation between semen volume (Spandorfer et al., 1998; Andolz et al., 1999; Moskovtsev et al., 2009; Brahem et al., 2011; Dain et al., 2011; Stone et al., 2013), motility (Moskovtsev et al., 2009; Winkle et al., 2009; Zhu et al., 2011; Stone et al., 2013) and sperm vitality (Moskovtsev et al., 2009; Brahem et al., 2011; Zhu et al., 2011; Stone et al., 2013) with male age. There is no consensus in the literature, as some authors have not observed any correlation between age and some of these semen parameters (Berling \& Wölner-Hanssen, 1997; Spandorfer et al., 1998; Frattarelli et al., 2008; Nijs et al., 2011; Fréour et al., 2012). Conversely, in this study, the sperm concentration did not show a significant variation with age, in agreement with previous studies that showed little or no association between age and sperm concentration (Spandorfer et al., 1998; Bellver et al., 2008; Frattarelli et al., 2008; Dain et al., 2011; Nijs et al., 2011; Fréour et al., 2012). There is again no consensus in the literature. Some studies have reported a decrease in the concentration of spermatozoa with increasing age (Luna et al., 2009; Stone et al., 2013), whereas others have observed an increase in sperm concentration (Andolz et al., 1999; Brahem et al., 2011). It should be noted, however, that the design of the different published studies and their respective populations are quite heterogeneous. Whereas some used volunteers, others based their research on populations under treatment in infertility clinics. This difference complicates the interpretation of these results.

The pathophysiology of the impact of age on semen parameters can occur due to both the specific effects of age alone and associated factors such as obesity, infections of the reproductive glands or the accumulation of toxic substances. It is important to note that a significant number of these studies did not control for potential confounding factors. In our study, factors such as tobacco and alcohol use, the presence of varicocele or the intake of vitamins did not appear to influence the results. Similarly, no differences were observed in the numbers of leukocytes in the semen. 

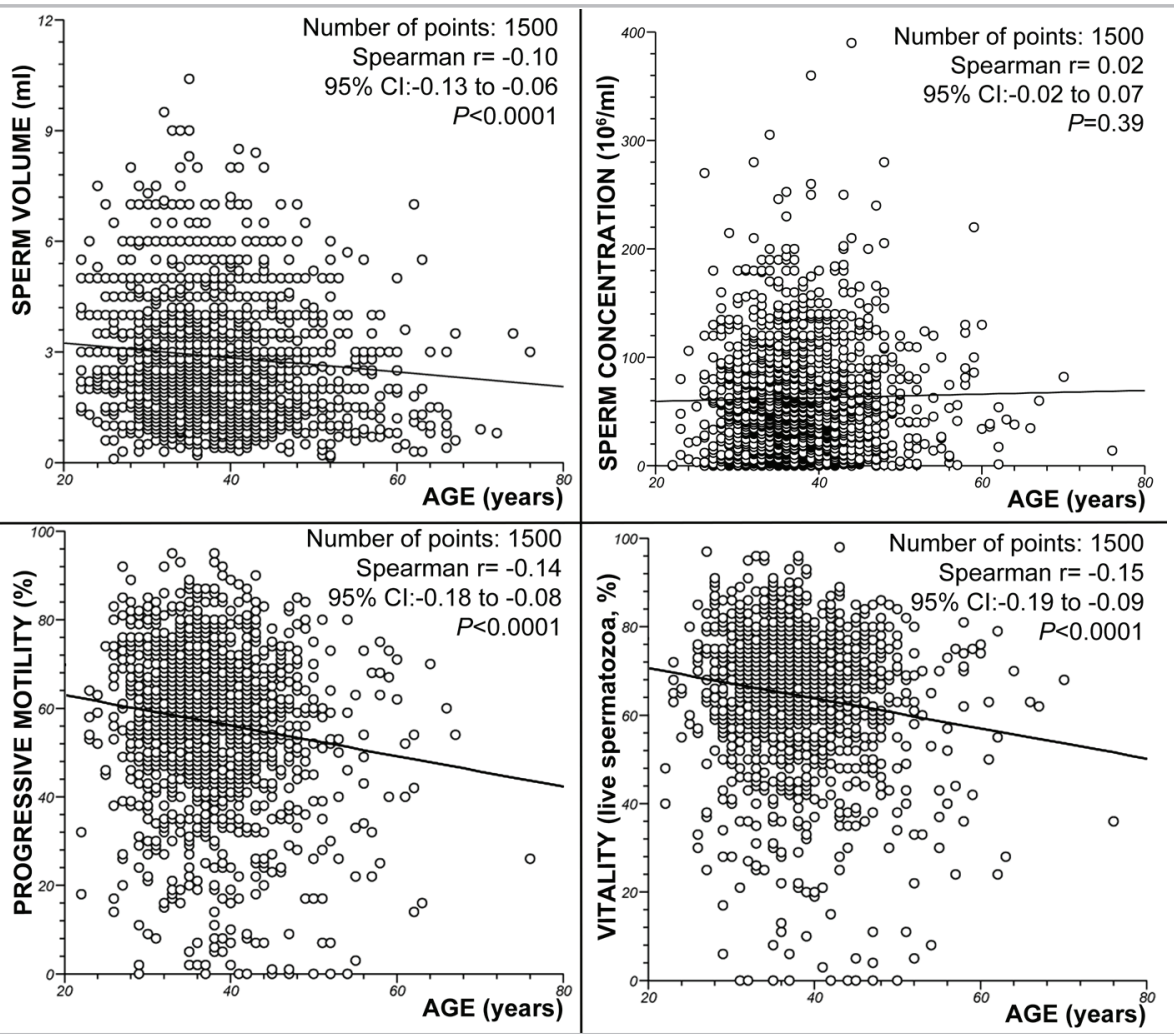

Figure 2. Spearman rank correlation test. Correlations between age and $\mathrm{pH}$, volume $(\mathrm{ml})$, sperm concentration $\left(x 10^{6} / \mathrm{ml}\right)$, percentage of spermatozoa with progressive motility (rapid + slow progression), number of leukocytes $\left(x 1^{6}\right)$ and percentage of live spermatozoa (vitality).
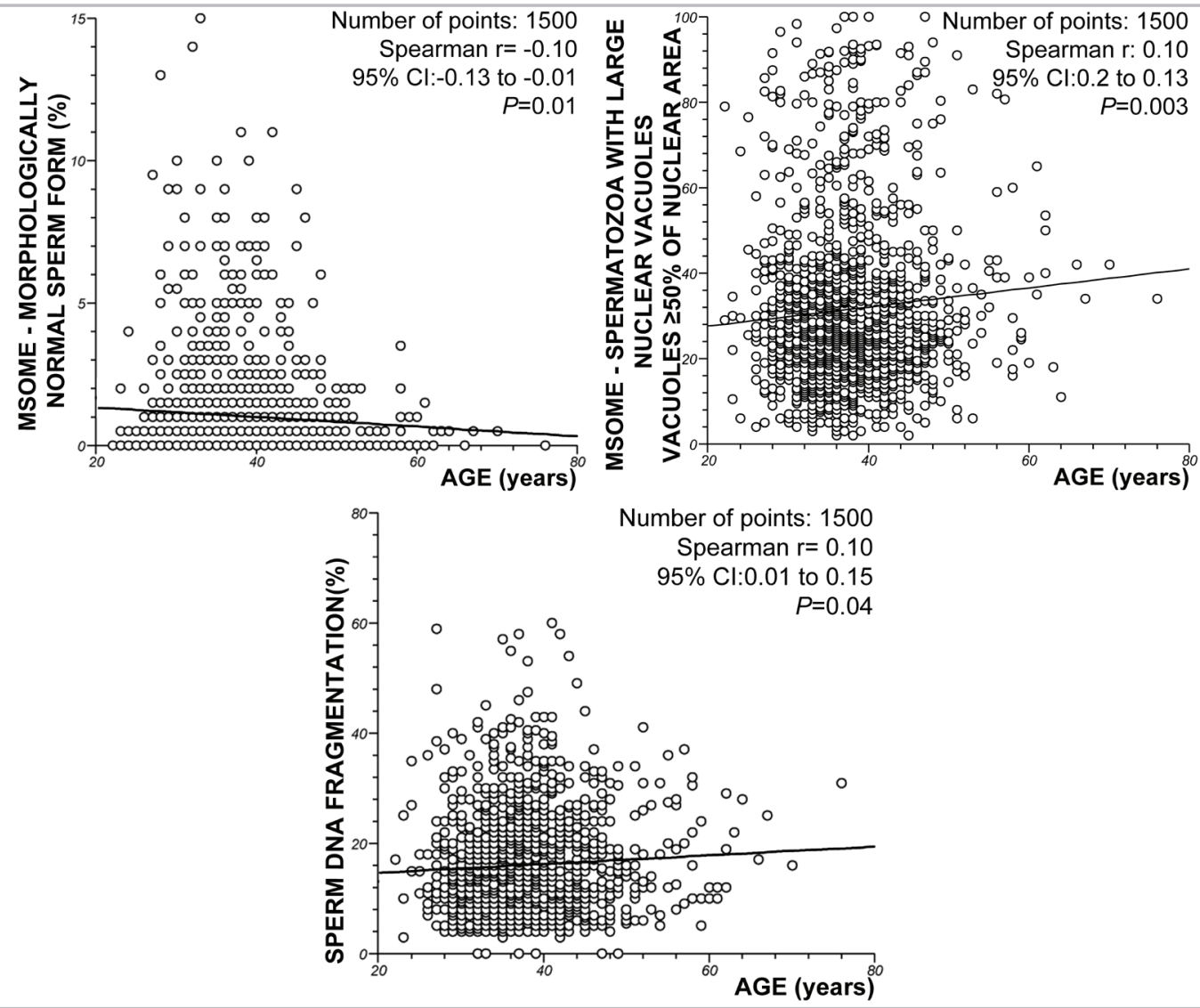

Figure 3. Spearman rank correlation test. Correlations between age and sperm morphology and sperm DNA fragmentation. 
Conversely, a longer duration of abstinence may be responsible for the differences in the results. The length of sexual abstinence was controlled (2-5 days) so that it would not bias the results. Further comparisons were made between the semen parameters to better evaluate the semen parameters and the different numbers of days of abstinence $(2,3,4$ and 5). No significant differences were observed. Innovative methods for selecting spermatozoa in assisted reproductive techniques (ARTs) have been published, providing new insights into the correlations between sperm quality and clinical outcomes. To test the hypothesis that the subtle defects in semen organelles are associated with the ART outcomes, Bartoov et al., (2002) proposed a novel method to morphologically evaluate sperm in real time and at high magnification ( $>6,000 \mathrm{x}$ ) called motile sperm organelle morphology examination (MSOME). In MSOME, the most important predictor of sperm quality is the extent of the impairment of the sperm head due to the presence of vacuoles. Vacuoles, which are best observed at high magnification, appear to correlate with abnormal chromatin packaging or the denaturation and fragmentation of sperm DNA (Franco et al., 2008, 2012; Boitrelle et al., 2013).

Regarding the morphology of the spermatozoa, our results show a significant decrease $(P=0.01)$ in the percentage of morphologically normal spermatozoa and a significant increase $(P=0.003)$ in the percentage of LNV spermatozoa with increasing age. These results confirm the previous evaluation by our group (Silva et al., 2012), which also showed a significant correlation between age and the percentages of normal spermatozoa and spermatozoa with LNVs $(r=-1.0, P=0.0015$ and $r=0: 1 \mathrm{~A} 0, P=0.0012$, respectively). Similar to the results of this study, Braga et al. (2011) analyzed the relationship between spermatozoa morphology evaluated using MSOME and age and reported a positive correlation between age and the presence of nuclear vacuoles (large vacuoles $P<0.001$; small vacuoles $P<0.001)$. However, these authors reported that there was no correlation between the frequency of morphologically normal spermatozoa, as defined by MSOME, and male age $(P=0.715)$. Importantly, these authors defined the MSOME criteria for morphological normality of the spermatozoa nuclei according to Cassuto et al., (2009), whereas we used the criteria proposed by Bartoov et al. (2002). This difference may explain the conflicting results. Unfortunately, MSOME is not normally used other than in the selection of spermatozoa for ART. Indeed, to our knowledge, only the cited studies examined the relationship between sperm morphology evaluated using MSOME and male age. Our results contrast with those of several studies that reported no relationship between age and sperm morphology (Kidd et al., 2001; Brahem et al., 2011; Dain et al., 2011; Nijs et al., 2011). But, variations in the criteria used to analyze the sperm morphology in each of these studies may explain this discrepancy (Kidd et al., 2001), especially considering that the count of specific abnormalities can vary depending on the classification used. Conversely, MSOME gives particular importance to the nuclear morphology of sperm. Our data are consistent with those of several other studies that used other semen morphological evaluation criteria besides MSOME (Andolz et al., 1999; Girsh et al., 2008; Zhu et al., 2011; Stone et al., 2013).

The present study also observed an increase in the fragmentation of sperm DNA associated with an increase in patient age. However, the impact of age on the fragmentation of sperm DNA still remains the object of study. Several techniques are currently available to evaluate damage to sperm DNA. Using the TUNEL assay, we found a significant positive association between paternal age and the levels of DNA fragmentation.

The correlation between age and sperm DNA fragmentation using the TUNEL assay was previously observed in a prior study by our group (Vagnini et al., 2007). Our results are not consistent with the data reported by Sun et al. (1997), Colin et al. (2010) and Brahem et al. (2011); they used the TUNEL assay and did not observe a significant relationship between age and DNA damage. Besides their sample sizes were much smaller (Sun et al., 1997; Colin et al., 2010; Brahem et al., 2011) than the sample size in the present study, DNA damage was evaluated after washing the sperm according to the swim-up method (Sun et al., 1997), a procedure that can significantly decrease the proportion of spermatozoa with DNA fragmentation. Furthermore, our results are consistent with the data reported by Plastira et al. (2007) and Varshini et al. (2012) who used the TUNEL assay and reported that male aging affects the integrity of spermatozoa chromatin in the infertile population. Likewise, other researchers (Singh et al., 2003; Sati et al., 2008; Moskovtsev et al., 2009) have reported results similar to our findings using different assays to measure sperm DNA damage in infertile and non-infertile populations. However other authors having reported conflicting results. Nijs et al. (2011) using the sperm chromatin structure assay (SCSA), reported no significant male age-related increase in the DNA fragmentation index (DFI). Moreover, Winkle et al. (2009), using propidium iodide staining and flow cytometry, reported that male age does not affect the number of spermatozoa with fragmented DNA. We should consider that the majority of studies show a direct correlation between male age and the damage of sperm DNA.

Variations in the results in the literature may be related to the technique used and/or the population analyzed.

Despite the majority of the correlations between age and sperm parameters being significant $(<0.05)$ in our study, they could be considered weak (Spearman's $r<0.4$ ). However, the correlations were quite similar to those found by different authors. Brahem et al., (2011) reported values of $r=-0.183(P=0.032), r=-0.219(P=0.001)$ and $\mathrm{r}=0.196(P=0.021)$ for the correlations between age and semen volume, vitality and sperm concentration, respectively. The relationship between sperm morphology and age was similar to those found by authors using different sperm classification criteria: Brahem et al. (2011) $r=0.026$, not significant; Andolz et al. (1999) $r^{2}=0.020$, $P<0.001$; and Braga et al. (2011) $r^{2}=0.118, P<0.001$. Similarly, for DNA fragmentation, other authors found results similar to ours: Sun et al. (1997), $r=0.06$, not significant; Moskovtsev et al. (2009), $r=0.24$, significant. On the other hand others have reported stronger correlations between age and DNA fragmentation: Singh et al. (2003), $r=0.56, P<0.001$; and Wyrobek et al. (2006), $r=0.64-$ $0.72, P<0.001$. It is likely that other factors influence the correlations between age and sperm parameters. Furthermore, differences in sample size, evaluation methods, and statistical analysis methods likely contribute to the differences between these studies. Unfortunately, not all studies have used this type of statistical analysis, which makes the interpretation of these correlation values challenging.

In conclusion, semen quality seems to be influenced by aging. The age-related decrease in sperm quality suggests that delaying childbearing, not only for women but also for men, may jeopardize reproductive capacity.

Considering the relationship with DNA damage, these age-related changes suggest that advanced paternal age may be associated with an increased risk of unsuccessful and abnormal pregnancy as a consequence of fertilization with damaged spermatozoa. This information may be useful in the clinical management of male infertility.

\section{CONFLICT OF INTERESTS}

The authors declare that they have no conflict of interest. 


\section{Acknowledgments}

The authors wish to thank the American Journal Experts for revising the English text.

\section{Corresponding author:}

Jose G Franco Jr

Center for Human Reproduction Prof. Franco Jr

Av. Joao Fiusa 689 - Ribeirao Preto, Sao Paulo, Brazil

Zip code: 14025310

E-mail: crh@crh.com.br

\section{REFERENCES}

Andolz P, Bielsa MA, Vila J. Evolution of semen quality in North-eastern Spain: a study in 22,759 infertile men over a 36 year period. Hum Reprod 1999;14:731-35.

Bartoov B, Berkovitz A, Eltes F, Kogosowski A, Menezo $Y$, Barak Y. Real-time fine morphology of motile human sperm cells is associated with IVF-ICSI outcome. J Androl 2002;23:1-8.

Bellver J, Garrido N, Remohí J, Pellicer A, Meseguer M. Influence of paternal age on assisted reproduction outcome. Reprod Biomed Online 2008;17:595-604.

Berling S, Wölner-Hanssen P. No evidence of deteriorating semen quality among men in infertile relationships during the last decade: a study of males from Southern Sweden. Hum Reprod 1997;12:1002-5.

Boitrelle F, Albert M, Petit JM, Ferfouri F, Wainer R, Bergere $M$, Bailly $M$, Vialard $F$, Selva J. Small human sperm vacuoles observed under high magnification are pocket-like nuclear concavities linked to chromatin condensation failure. Reprod Biomed Online 2013;27:201-11.

Brahem S, Mehdi M, Elghezal $H$, Saad A. The effects of male aging on semen quality, sperm DNA fragmentation and chromosomal abnormalities in an infertile population. J Assist Reprod Genet 2011;28:425-32.

Braga DPAF, Setti AS, Figueira RCS, Nichi M, Martinhago $C D$, Iaconelli $A$, Borges $E$. Sperm organelle morphologic abnormalities: Contributing factors and effects on intracytoplasmic sperm injection cycles outcomes. Urology 2011;78:786-91

Cassuto NG, Bouret D, Plouchart JM, Jellad S, Vanderzwalmen $P$, Balet $R$, Larue $L$, Barak $Y$. A new real-time morphology classification for human spermatozoa: a link for fertilization and improved embryo quality. Fertil Steril 2009; $92: 1616-25$.

Colin A, Barroso G, Gómez-López N, Duran EH, Oehninger $\mathrm{S}$. The effect of age on the expression of apoptosis biomarkers in human spermatozoa. Fertil Steril 2010;94:2609-14.

Crosnoe LE, Kim ED. Impact of age on male fertility. Curr Opin Obstet Gynecol 2013;25:181-5.

Dain L, Auslander R, Dirnfeld M. The effect of paternal age on assisted reproduction outcome. Fertil Steril 2011;95:1-8.

Das M, Al-Hathal N, San-Gabriel M, Phillips S, Kadoch I-J, Bissonnette $\mathrm{F}$, Holzer $\mathrm{H}$, Zini A. High prevalence of isolated sperm DNA damage in infertile men with advanced paternal age. J Assist Reprod Genet 2013;30:843-8.

Franco JG, Baruffi RLR, Mauri AL, Petersen CG, Oliveira JBA, Vagnini L. Significance of large nucle- ar vacuoles in human spermatozoa: implications for ICSI. Reprod Biomed Online 2008;17:42-5.

Franco JG, Mauri AL, Petersen CG, Massaro FC, Silva LFI, Felipe V, Cavagna M, Pontes A, Baruffi RLR, Oliveira JBA. Large nuclear vacuoles are indicative of abnormal chromatin packaging in human spermatozoa. Int $\mathrm{J}$ Androl 2012;35:46-51.

Frattarelli JL, Miller KA, Miller BT, Elkind-Hirsch K, Scott RT. Male age negatively impacts embryo development and reproductive outcome in donor oocyte assisted reproductive technology cycles. Fertil Steril 2008;90:97-103.

Fréour $\mathrm{T}$, Jean $\mathrm{M}$, Mirallie $\mathrm{S}$, Barriere $\mathrm{P}$. Computer-assisted sperm analysis parameters in young fertile sperm donors and relationship with age. Syst Biol Reprod Med 2012;58:102-6.

Girsh E, Katz N, Genkin L, Girtler O, Bocker J, Bezdin S, Barr I. Male age influences oocyte-donor program results. ] Assist Reprod Genet 2008;25:137-43.

Kidd SA, Eskenazi B, Wyrobek AJ. Effects of male age on semen quality and fertility: A review of the literature. Fertil Steril $2001 ; 75: 237-48$.

Kleinhaus K, Perrin M, Friedlander Y, Paltiel O, Malaspina D, Harlap S. Paternal age and spontaneous abortion. Obstet Gynecol 2006;108:369-77.

Luna M, Finkler E, Barritt J, Bar-Chama N, Sandler B, Copperman AB, Grunfeld L. Paternal age and assisted reproductive technology outcome in ovum recipients. Fertil Steril 2009; 92:1772-75.

Ménézo YJR, Hazout A, Panteix G, Robert F, Rollet J, Cohen-Bacrie $P$, Chapuis F, Clément $P$, Benkhalifa M. Antioxidants to reduce sperm DNA fragmentation: an unexpected adverse effect. Reprod Biomed Online 2007;14:418-21.

Moskovtsev SI, Willis J, White J, Mullen JBM. Sperm DNA Damage: Correlation to Severity of Semen Abnormalities. Urology 2009;74:789-93.

Nijs $M$, Jonge $C$ De, Cox $A$, Janssen $M$, Bosmans $E$, Ombelet W. Correlation between male age, WHO sperm parameters, DNA fragmentation, chromatin packaging and outcome in assisted reproduction technology. Andrologia 2011;43:174-9.

Paul C, Robaire B. Ageing of the male germ line. Nat Rev Urol 2013;1-8.

Plastira K, Msaouel P, Angelopoulou R, Zanioti K, Plastiras A, Pothos A, Bolaris S, Paparisteidis N, Mantas D. The effects of age on DNA fragmentation, chromatin packaging and conventional semen parameters in spermatozoa of oligoasthenoteratozoospermic patients. J Assist Reprod Genet 2007;24:437-43.

Sati L, Ovari L, Bennett D, Simon SD, Demir R, Huszar G. Double probing of human spermatozoa for persistent histones, surplus cytoplasm, apoptosis and DNA fragmentation. Reprod Biomed Online 2008;16:570-9.

Silva LFI, Oliveira JB a, Petersen CG, Mauri AL, Massaro FC, Cavagna M, Baruffi RLR, Franco JG. The effects of male age on sperm analysis by motile sperm organelle morphology examination (MSOME). Reprod Biol Endocrinol 2012;10:19. 
Singh NP, Muller $\mathrm{CH}$, Berger RE. Effects of age on DNA double-strand breaks and apoptosis in human sperm. Fertil Steril 2003;80:1420-30.

Slama R, Bouyer J, Windham G, Fenster L, Werwatz A, Swan SH. Influence of paternal age on the risk of spontaneous abortion. Am J Epidemiol 2005;161:816-23.

Spandorfer SD, Avrech OM, Colombero LT, Palermo GD, Rosenwaks Z. Effect of parental age on fertilization and pregnancy characteristics in couples treated by intracytoplasmic sperm injection. Hum Reprod 1998;13:334-8.

Stone BA, Alex A, Werlin LB, Marrs RP. Age thresholds for changes in semen parameters in men. Fertil Steril 2013;100:952-8.

Sun JG, Jurisicova A, Casper RF. Detection of deoxyribonucleic acid fragmentation in human sperm: correlation with fertilization in vitro. Biol Reprod 1997;56:602-7.

Urhoj SK, Jespersen LN, Nissen M, Mortensen LH, Nybo Andersen a-M. Advanced paternal age and mortality of offspring under 5 years of age: a register-based cohort study. Hum Reprod 2014;29:343-50.

Vagnini L, Baruffi RLR, Mauri AL, Petersen CG, Massaro FC, Pontes A, Oliveira JBA, Franco JG. The effects of male age on sperm DNA damage in an infer- tile population. Reprod Biomed Online 2007;15:514-9.

Varshini J, Srinag BS, Kalthur G, Krishnamurthy H, Kumar P, Rao SB, Adiga SK. Poor sperm quality and advancing age are associated with increased sperm DNA damage in infertile men. Andrologia 2012;44:642-9.

WHO World Health Orgnization. WHO Laboratory manual for the examination and processing of human semen. $5^{\text {th }}$ Edition Geneva: WHO; 2010.

Winkle T, Rosenbusch B, Gagsteiger F, Paiss T, Zoller N. The correlation between male age, sperm quality and sperm DNA fragmentation in 320 men attending a fertility center. J Assist Reprod Genet 2009;26:41-6.

Wyrobek AJ, Eskenazi B, Young S, Arnheim N, Tiemann-Boege I, Jabs EW, Glaser RL, Pearson FS, Evenson D. Advancing age has differential effects on DNA damage, chromatin integrity, gene mutations, and aneuploidies in sperm. Proc Natl Acad Sci U S A 2006;103:9601-6.

Zhu Q-X, Meads C, Lu M-L, Wu J-Q, Zhou W-J, Gao E-S. Turning point of age for semen quality: a population-based study in Chinese men. Fertil Steril 2011;96:572-6.

Zini A, Libman J. Sperm DNA damage: importance in the era of assisted reproduction. Curr Opin Urol 2006;16:42834. 